\title{
Recent Research on the Deformation Behavior of Particle Reinforced Magnesium Matrix Composite: A Review
}

\author{
Kun-Kun Deng ${ }^{1} \cdot$ Cui-Ju Wang $^{1} \cdot$ Kai-Bo Nie $^{1} \cdot$ Xiao-Jun Wang ${ }^{2}$ \\ Received: 12 August 2018 / Revised: 9 December 2018 / Published online: 4 February 2019 \\ (C) The Chinese Society for Metals (CSM) and Springer-Verlag GmbH Germany, part of Springer Nature 2019
}

\begin{abstract}
Particle reinforced magnesium matrix composite (PMMC) possesses the merits of high specific strength, high specific modulus, better dimensional stability, good wear resistance and lower production cost, which is thought as a promising material in the field of aerospace, automobile, electronic communication, etc. To eliminate the casting defect, the PMMC is usually experienced hot deformation process. The present paper mainly focuses on the deformation behavior of PMMCs. First, the development of PMMCs based on particle size is introduced. Then, the hot deformation technology and deformation mechanism of PMMCs at elevated temperature are given and analyzed, respectively. After reviewing the dynamic recrystallization and texture of PMMCs, its future development is suggested based on the current research progress.
\end{abstract}

Keywords Magnesium matrix composite $\cdot$ Particle $\cdot$ Hot deformation $\cdot$ Deformation mechanism $\cdot$ Recrystallization

\section{Introduction}

As the lightest metal structural material available in nature, magnesium alloy had attracted much more attention in the field of aerospace, automobile, electronic communication, etc [1-4]. However, the low modulus, low wear resistance, high coefficient of thermal expansion and poor high-temperature performance of magnesium alloy limit its application in industrial engineering. Particle reinforced magnesium matrix composites (PMMCs) not only have the advantage of magnesium alloy, but also possess the merits of high specific strength, high specific modulus, better dimensional stability, good wear resistance and lower production cost, which are thought as a promising material in the field of light weight [5-7].

The PMMCs can be processed by a variety of ways, such as power metallurgy $[8,9]$, in situ reaction $[10,11]$, spray

Available online at http://link.springer.com/journal/40195

Kun-Kun Deng

jamsdk@163.com

1 Shanxi Key Laboratory of Advanced Magnesium-Based Materials, College of Materials Science and Engineering, Taiyuan University of Technology, Taiyuan 030024, China

2 School of Materials Science and Engineering, Harbin Institute of Technology, Harbin 150001, China forming [12], squeeze casting [13] and stir casting [14, 15]. To eliminate the casting defect, the PMMCs are usually deformed by forging, extrusion, rolling, etc. During these processes, the grains are refined and the particle distribution is improved simultaneously, both of which contribute to the improved strength of PMMCs. It is known that dynamic recrystallization (DRX) occurs during hot deformation process. The existence of harden particle can not only influence the occurrence of DRX but also affect the deformation behavior of PMMCs. Thus, a large number of researchers have been intrigued in this aspect of PMMCs. This paper cannot include all the research aspects of PMMCs. Considering the fabrication process of PMMCs has been summarized in detail by Chen and Yao's work [16], the present work mainly focuses on the deformation technology, hot deformation mechanism, DRX behavior and prospects of PMMCs.

\section{Development of PMMCs Based on Particle Size}

In general, the mechanical properties of PMMCs strongly depend on the particle size, upon which the PMMCs can be divided into nano-, submicron and micron particle reinforced magnesium matrix composite, respectively. 
Owing to the easy fabrication process, the research of micron PMMCs began much earlier than nano- and submicron PMMCs. Cai et al. [17] fabricated the 15 vol\% $10 \mu \mathrm{m}$ $\mathrm{SiC}_{\mathrm{p}} / \mathrm{Mg}$ composite through stir casting technology, and it was found that most of the $\mathrm{SiC}_{\mathrm{p}}$ distributed along grain boundaries and only a little amount ( $3 \mathrm{vol} \%$ ) of them located at the interior of grains. Nevertheless, Cai et al. [17] pointed out that the thermal expansion could be generated between micron $\mathrm{SiCp}$ and $\mathrm{Mg}$ matrix due to the different thermal expansion coefficients, which originated from the heterogeneous nucleation of $\mathrm{Mg}$ during solidification process. Wang et al. $[15,18]$ also fabricated micron $\mathrm{SiC}_{\mathrm{p}} / \mathrm{AZ} 91$ composite by stir casting technology, and the micron $\mathrm{SiC}_{\mathrm{p}}$ was found at grain boundaries with "necklace" distribution. Such kind of particle distribution was thought easy to generate stress concentration and resulted in the initiation of microcrack
$[15,18]$. As a conclusion, the "necklace" particle distribution and weaker interfacial bonding between $\mathrm{SiC}_{\mathrm{p}}$ and $\mathrm{Mg}$ were responsible for the undesirable mechanical properties of PMMCs fabricated by stir casting technology [15, 18]. Subsequently, the researchers tried to ameliorate the manufacturing process of PMMCs for improving the mechanical properties of micron PMMCs. As compared with conventional stir casting, the compound casting was thought as an effective way to improve the mechanical properties of PMMCs [19]. In the latest work of Wang et al. [20], the combination of semisolid stirring casting and ultrasonic dispersion was used to fabricate the micron PMMCs. It was found that the compound casting methods had obvious effect on the improvement of the particle distribution and the increases of the yield strength (YS) and ultimate tensile strength (UTS) of PMMCs [20], as shown in Table 1.

Table 1 Tensile properties of PMMCs obtained from reference

\begin{tabular}{|c|c|c|c|c|c|}
\hline Materials & YS (MPa) & UTS (MPa) & Modulus (GPa) & Elongation (\%) & References \\
\hline AZ91 & $\sim 75$ & $\sim 128$ & $\sim 46$ & $\sim 2.05$ & {$[20]$} \\
\hline 5 vol\% $10 \mu \mathrm{m} \mathrm{SiCp/AZ91}$ & $\sim 110$ & $\sim 131$ & $\sim 50$ & $\sim 1.6$ & {$[20]$} \\
\hline 10 vol\% $10 \mu \mathrm{m}$ SiCp/AZ91 & $\sim 120$ & $\sim 172$ & $\sim 55$ & $\sim 1.4$ & {$[20]$} \\
\hline 15 vol\% $10 \mu \mathrm{m} \mathrm{SiCp/AZ91}$ & $\sim 145$ & $\sim 200$ & $\sim 62$ & $\sim 1.15$ & {$[20]$} \\
\hline 20 vol\% $10 \mu \mathrm{m}$ SiCp/AZ91 & $\sim 169$ & $\sim 192$ & $\sim 71$ & $\sim 0.6$ & {$[20]$} \\
\hline 25 vol\% $15 \mu \mathrm{m}$ SiCp/AZ91 & $\sim 310$ & $\sim 330$ & $\sim 78$ & $\sim 0.8$ & {$[21]$} \\
\hline 25 vol\% $52 \mu \mathrm{m} \mathrm{SiCp/AZ91}$ & $\sim 290$ & $\sim 340$ & $\sim 79$ & $\sim 1.1$ & {$[21]$} \\
\hline 20 vol\% $15 \mu \mathrm{m} \mathrm{SiCp/AZ91}$ & $\sim 330$ & $\sim 390$ & $\sim 71$ & $\sim 1.3$ & {$[21]$} \\
\hline 20 vol\% $52 \mu \mathrm{m}$ SiCp/AZ91 & $\sim 270$ & $\sim 320$ & $\sim 72$ & $\sim 1.1$ & {$[21]$} \\
\hline 1 vol\% 60 nm SiCp/AZ91 & $\sim 85$ & $\sim 180$ & - & $\sim 5$ & {$[24]$} \\
\hline $0.5 \mathrm{wt} \% 60 \mu \mathrm{m} \mathrm{Al}{ }_{2} \mathrm{O}_{3} / \mathrm{Mg}$ & $\sim 169$ & $\sim 232$ & $\sim 42.5$ & $\sim 6.5$ & {$[25]$} \\
\hline $1.5 \mathrm{wt} \% 60 \mu \mathrm{m} \mathrm{Al}{ }_{2} \mathrm{O}_{3} / \mathrm{Mg}$ & $\sim 191$ & $\sim 247$ & $\sim 43.4$ & $\sim 8.8$ & [25] \\
\hline $2.5 \mathrm{wt} \% 60 \mu \mathrm{m} \mathrm{Al}{ }_{2} \mathrm{O}_{3} / \mathrm{Mg}$ & $\sim 194$ & $\sim 250$ & $\sim 44.5$ & $\sim 6.9$ & {$[25]$} \\
\hline 0.35 vol\% $(45 \sim 55 \mathrm{~nm}) \mathrm{SiCp} / \mathrm{Mg}$ & $\sim 116$ & $\sim 169$ & - & $\sim 5.2$ & {$[26]$} \\
\hline 0.5 vol\% $(45 \sim 55 \mathrm{~nm}) \mathrm{SiCp} / \mathrm{Mg}$ & $\sim 107$ & $\sim 161$ & - & $\sim 6.5$ & {$[26]$} \\
\hline 1.0 vol\% $(45 \sim 55 \mathrm{~nm}) \mathrm{SiCp} / \mathrm{Mg}$ & $\sim 125$ & $\sim 181$ & - & $\sim 6.1$ & {$[26]$} \\
\hline 3 vol\% $1 \mu \mathrm{m} \mathrm{SiCp/AZ91}$ & $\sim 99$ & $\sim 150$ & - & $\sim 2$ & [29] \\
\hline 5 vol\% $1 \mu \mathrm{m} \mathrm{SiCp/AZ91}$ & $\sim 108$ & $\sim 140$ & - & $\sim 0.8$ & [29] \\
\hline $0.5 \mathrm{vol} \%(32 \sim 36 \mathrm{~nm}) \mathrm{Y}_{2} \mathrm{O}_{3} / \mathrm{Mg}$ & $\sim 141$ & $\sim 223$ & - & $\sim 8.5$ & {$[31]$} \\
\hline $1 \mathrm{vol} \%(32 \sim 36 \mathrm{~nm}) \mathrm{Y}_{2} \mathrm{O}_{3} / \mathrm{Mg}$ & $\sim 151$ & $\sim 222$ & - & $\sim 6.8$ & {$[31]$} \\
\hline 2 vol\% $(32 \sim 36 \mathrm{~nm}) \mathrm{Y}_{2} \mathrm{O}_{3} / \mathrm{Mg}$ & $\sim 162$ & $\sim 227$ & - & $\sim 7.0$ & {$[31]$} \\
\hline $1.5 \mathrm{wt} \% 36 \mathrm{~nm} \mathrm{Al}_{2} \mathrm{O}_{3} / \mathrm{Mg}$ & $\sim 214$ & $\sim 261$ & - & $\sim 12.5$ & {$[34]$} \\
\hline $2.5 \mathrm{wt} \% 36 \mathrm{~nm} \mathrm{Al}_{2} \mathrm{O}_{3} / \mathrm{Mg}$ & $\sim 200$ & $\sim 256$ & - & $\sim 8.6$ & {$[34]$} \\
\hline $5.5 \mathrm{wt} \% 36 \mathrm{~nm} \mathrm{Al}_{2} \mathrm{O}_{3} / \mathrm{Mg}$ & $\sim 222$ & $\sim 281$ & - & $\sim 4.5$ & {$[34]$} \\
\hline 1 vol\% $0.2 \mu \mathrm{m} \mathrm{SiCp/AZ91}$ & $\sim 275.3$ & $\sim 335.4$ & $\sim 45.5$ & $\sim 2.43$ & {$[37]$} \\
\hline 1 vol\% $0.2 \mu \mathrm{m}+9$ vol $\% 10 \mu \mathrm{m}$ SiCp/AZ91 & $\sim 328.8$ & $\sim 360.1$ & $\sim 61$ & $\sim 1.28$ & {$[37]$} \\
\hline 10 vol\% $10 \mu \mathrm{m}$ SiCp/AZ91 & $\sim 283.1$ & $\sim 347.6$ & $\sim 60.2$ & $\sim 1.18$ & {$[37]$} \\
\hline $1 \mathrm{vol} \% 60 \mathrm{~nm}+14$ vol\% $10 \mu \mathrm{m} \mathrm{SiCp/AZ31B}$ & $\sim 210$ & $\sim 295$ & - & $\sim 6.5$ & {$[38]$} \\
\hline 1 vol\% $60 \mathrm{~nm}+9$ vol\% $10 \mu \mathrm{m} \mathrm{SiCp/AZ31B}$ & $\sim 225$ & $\sim 305$ & - & $\sim 3.9$ & {$[38]$} \\
\hline 1 vol\% $60 \mathrm{~nm}+4$ vol\% $10 \mu \mathrm{m}$ SiCp/AZ31B & $\sim 275$ & $\sim 350$ & - & $\sim 3.1$ & {$[38]$} \\
\hline $5.6 \mathrm{wt} \% \mathrm{Ti} / \mathrm{Mg}$ & $\sim 158$ & $\sim 226$ & & $\sim 8$ & [40] \\
\hline $5.6 \mathrm{wt} \% \mathrm{Ti}+2.5 \mathrm{wt} \% \mathrm{~B}_{4} \mathrm{C} / \mathrm{Mg}$ & $\sim 215$ & $\sim 260$ & & $\sim 8.1$ & {$[40]$} \\
\hline
\end{tabular}


The micron particles can play a significant role in improving the modulus and strength of PMMCs, but reduced the elongation of $\mathrm{Mg}$ matrix [21]. The decreasing size of micron particle can not only improve the strength of PMMCs but also lead to the increase in elongation. A little amount of micron $(1-2 \mu \mathrm{m}) \mathrm{SiCp}$ was added into AZ91 alloy by Chen et al. [22], and then the PMMCs with finer grains as well as the better strength and ductility were obtained. As the particle size is finer than $1 \mu \mathrm{m}$, the interfacial bonding between the particle and $\mathrm{Mg}$ matrix becomes well owing to the less surface defects around the particles, which will strengthen the load transfer effect. In particular, the nanoparticles usually exhibit excellent strengthening effects due to their unique scale effects [23, 24]. The investigation of Hassan et al. [25] proved that the $\mathrm{Mg}$ with $0.66 \mathrm{vol} \%$ and $1.11 \mathrm{vol} \%$ nano- $\mathrm{Al}_{2} \mathrm{O}_{3 \mathrm{p}}$ possess the higher YS and UTS than that with high content micron particles.

In addition, it was found that the nanoparticles can not only increase the strength of $\mathrm{Mg}$ matrix but also improve its plasticity remarkably [25-28]. The combination of semisolid stirring casting and ultrasonic dispersion method was adopted to fabricate nano-SiC $/ \mathrm{AZ} 91$ composite, and the results indicated that the composite not only possess uniform nanoparticle distribution but also own high strength and desirable ductility [29]. The main strengthening mechanisms of nano-PMMCs were classified as Orowan strengthening and fine grain strengthening according to the investigation on nano- $\mathrm{Al}_{2} \mathrm{O}_{3 \mathrm{p}} / \mathrm{Mg}$ composite [30]. Moreover, Goh et al. [31] found that the nanoparticles can not only improve the mechanical properties but also enhance the thermostability of $\mathrm{Mg}$ alloy. Nevertheless, Radi et al. thought that the contribution of nanoparticles to the high-temperature microstructure stability of $\mathrm{Mg}$ matrix derives from their pinning effect on grain boundaries and hindering effect on dislocation movement [32].

Apart from adding particles, the $\mathrm{TiC}_{\mathrm{p}}$ with the size of 3-7 nm were obtained by Hwang and Nishimura [33] through chemical reaction of $\mathrm{Ti}$ and $\mathrm{C}$ powder. Then, the nano- $\mathrm{TiC}_{\mathrm{p}} / \mathrm{Mg}$ composite with better strength and ductility was obtained [33]. However, considering the high cost of nanoparticles, some researchers carried out the exploration of submicron PMMCs. Hassan et al. [34] studied the effect of submicron $\mathrm{Al}_{2} \mathrm{O}_{3 p}$ on the microstructure and tensile properties of $\mathrm{Mg}$ matrix and found that the strengthening effect of submicron $\mathrm{Al}_{2} \mathrm{O}_{3 \mathrm{p}}$ was better than that of nanoparticles. Deng et al. [35] fabricated the submicron $\mathrm{SiC}_{\mathrm{p}} / \mathrm{AZ} 91$ composite through stir casting, and the results proved that the submicron $\mathrm{SiCp}$ can improve the mechanical properties of AZ91 significantly. However, the strengthening effect of submicron particle on $\mathrm{Mg}$ matrix depends on its volume fraction. Deng et al. [35] found that the severe submicron particle agglomeration appeared and the strength of submicron PMMCs decreased once the volume fraction of submicron $\mathrm{SiC}_{\mathrm{p}}$ was higher than $2 \%$. The research of Ferkel et al. on nanoparticles also confirmed that the effective volume fraction of submicron particle was no more than $2 \%$ [36].

The elastic modulus of PMMCs is closely related to particle content. The higher particle content in PMMCs exhibits the higher modulus of PMMCs. Although nano- and submicron particles can greatly enhance the strength and ductility of $\mathrm{Mg}$ matrix, the higher volume fraction of nano- or submicron PMMCs is difficult to fabricate. Therefore, the single-sized nano- or submicron particles usually make a little contribution to the modulus of PMMCs. To give full play to the strengthening effects of different sized particles, Deng et al. [37] fabricated PMMCs with bimodal-sized particles through mixing 1 vol\% submicron $\mathrm{SiC}_{\mathrm{p}}$ and 9 vol\% micron $\mathrm{SiC}_{\mathrm{p}}$, the tensile properties of which are given in Table 2. It shows clearly that the PMMCs with bimodalsized particles exhibit better tensile properties than those with single-sized particles. Shen et al. [38] also fabricated bimodal-sized PMMCs through mixing nano- and submicron particles, and then the same conclusions as Deng et al. were also obtained. Recently, Sankaranarayanan et al. fabricated (nano-SiC $\mathrm{p}_{\mathrm{p}}+$ micron $\mathrm{Ti}_{\mathrm{p}}$ )/ $\mathrm{Mg}$ [39] and (nano- $\mathrm{B}_{4} \mathrm{C}_{\mathrm{p}}+$ micron $\left.\mathrm{Ti}_{\mathrm{p}}\right) / \mathrm{Mg}$ [40] composite, and the similar results were obtained showing that the bimodal-sized PMMCs possess better mechanical properties than the PMMCs with singlesized particle.

\section{Hot Deformation Technology of PMMCs}

Usually, only basal slip system (0001) $\langle 11 \overline{2} 0\rangle$ can occur in $\mathrm{Mg}$ at room temperature [41]. As the limited slip system, the plasticity of $\mathrm{Mg}$ is poor. At high temperature, apart from basal slip system, prismatic slip system $\{10 \overline{1} 0\}\langle 11 \overline{2} 0\rangle$ and pyramidal slip system $\{10 \overline{1} 1\}\langle 11 \overline{2} 0\rangle$ can operate, both of which contribute to the higher plastic deformation ability of Mg. Nevertheless, the PMMCs will possess fine grains, uniform particle distribution and higher mechanical properties after being deformed at high temperatures. The common
Table 2 Mechanical properties of the $\mathrm{SiCp} / \mathrm{AZ} 91$ composites after hot deformation. Reproduced from [37], with permission from Elsevier

\begin{tabular}{lcccc}
\hline Materials & YS (MPa) & UTS (MPa) & Modulus (GPa) & Elongation (\%) \\
\hline $0.2 \mu \mathrm{m} \mathrm{1 \%}$ & $275.3 \pm 5.2$ & $335.4 \pm 4.3$ & $45.5 \pm 0.72$ & $2.43 \pm 0.55$ \\
$0.2 \mu \mathrm{m} \mathrm{1} \%+10 \mu \mathrm{m} \mathrm{9 \%}$ & $328.8 \pm 1.9$ & $360.1 \pm 2.2$ & $61 \pm 0.76$ & $1.28 \pm 0.05$ \\
$10 \mu \mathrm{m} \mathrm{10 \%}$ & $283.1 \pm 5.1$ & $347.6 \pm 5.2$ & $60.2 \pm 2.23$ & $1.18 \pm 0.27$ \\
\hline
\end{tabular}


deformation methods used on PMMCs include ECAP, forging, extrusion and rolling, etc.

\subsection{Equal Channel Angular Pressing}

Equal channel angular pressing (ECAP) refers to a process in which material is subjected to strong shear deformation at the corner of the mold, and the cross-sectional dimensions remains basically unchanged. Hence, it can be conducted repeatedly and accumulated a lager strain. A lot of works have been carried out about the effect of ECAP on Mg alloy [42-49]. The results reveled that both the strength and ductility of $\mathrm{Mg}$ alloy can be greatly improved after the application of ECAP process owing to obvious grain refinement. According to the paths during ECAP process, the ECAP can be executed through four ways: path A, path Bc, path $\mathrm{Ba}$ and path $\mathrm{C}$. Previous work showed that the ECAP paths have significant effect on the start of slip system, grain refinement, morphology and distribution of the phase, all of which would directly related to the material's mechanical properties [50-53].

Currently, the ECAP process is mainly applied on $\mathrm{Mg}$ alloy, and there are only a few researches on PMMCs processed by ECAP. Jia et al. [54] carried out ECAP on the $\mathrm{Mg}_{2} \mathrm{Si}_{\mathrm{p}} / \mathrm{ZK} 60$ composites, the results indicated that the UTS was increased from 154.8 to $270 \mathrm{MPa}$, and the elongation was improved from 4.5 to $17.5 \%$ after four passes of ECAP. Gan et al. [55] performed ECAP on the in situ $\mathrm{Mg}_{2} \mathrm{Sip} /$ $\mathrm{Mg}$ composites and found that the grain of $\mathrm{Mg}$ matrix was refined and the intensity strength of (0002) basal plane texture was weakened after the application of ECAP process. However, it was interesting to note that the grain size of $\mathrm{Mg}$ matrix changed a little during the subsequent ECAP process [55].

\subsection{Forging}

Pervious work has confirmed that the PMMCs could also be deformed by forging process. Deng et al. [56] forged $10 \mu \mathrm{m} 10 \% \mathrm{SiCp} / \mathrm{AZ} 91$ composite with the deformation strain of $50 \%$ at different temperatures. Then, the effect of forging temperature on the particle distribution, grain size, texture and tensile properties of the SiCp/AZ91 composites was investigated, and the best primary forging temperature for $\mathrm{SiCp} / \mathrm{AZ} 91$ composites was $420{ }^{\circ} \mathrm{C}$ [56]. Subsequently, the further work of Deng et al. focused on the effect of forging strain on the SiCp/AZ91 composite at the forging temperature of $420{ }^{\circ} \mathrm{C}$ [57]. Results demonstrated that the texture intensity increased significantly accompanied with increasing forging stain; however, the tensile properties were deteriorated as the strain increased from 60 to $80 \%$ owing to the occurrence of SiCp's agglomeration [57]. Above phenomenon indicated that the PMMCs are sensitive to both the temperature and strain during one-step forging process.

Besides one-step forging, the multidirectional forging (MDF) was applied to nano-SiCp/AZ91 composite by Nie et al. [58], and they found that the grain size of the composite was refined after one-step MDF. However, the grain size was not decreased monotonously with increasing MDF passes, and the grains grew up inversely after 3 passes of MDF. The authors thought that both the strain accumulation and nucleation driving force increased with increasing MDF passes, which would resulted in the increase in both nucleation rate and growth rate of the DRXed grain. Once the growth rate of DRXed grain is larger than that of nucleation rate, the average size of DRXed grain will grow up. After the application of MDF, the tensile strength of nanoSiCp/AZ91 composites was improved significantly, which was attributed to grain refinement and Orowan strengthening according to the investigation of Nie et al. [58].

Moreover, cyclic die forging (CCDF) was performed on nano-SiCp/Mg matrix composite in recent years [59]. After forging at $400{ }^{\circ} \mathrm{C}$ for 3 passes, the grain size was decreased to $\sim 2.5 \mu \mathrm{m}$ accompanying with the disappearance of $\mathrm{Mg}_{17} \mathrm{Al}_{12}$ phase. As the forging temperature decreased to $300{ }^{\circ} \mathrm{C}$, the $\mathrm{Mg}_{17} \mathrm{Al}_{12}$ phase precipitated again and the grain size was refined to $\sim 650 \mathrm{~nm}$ after twice CCDF [59]. Simultaneously, the application of CCDF was also propitious to the distribution of nano-SiCp leading to the better YS and UTS of nano-PMMCs [59]. The nano-SiCp/AZ91 composites were performed through CCDF by Guo et al. [60], they found that the grains of $\mathrm{Mg}$ matrix were remarkably refined, and the strength as well as elongation was both improved significantly after 5 passes. During the CCDF process, the agglomerated nano-SiCp was broken by matrix flow and distributed dispersive in the $\mathrm{Mg}$ matrix; however, the nano-SiCp agglomeration region cannot be completely eliminated due to the high surface energy of nano-SiCp [60]. In addition, the AZ31-Si composite was also forged through CCDF by Guo et al. [61], and they found that the $\mathrm{Mg}_{2} \mathrm{Si}$ particle was broken under the shear stress of matrix during forging process. Accompanied with increasing CCDF pass, the grain was refined and the distribution of $\mathrm{Mg}_{2} \mathrm{Si}$ became more uniform, both of which contributed to the improvement in mechanical properties [61].

\subsection{Extrusion}

As a conventional hot deformation process, extrusion has been used widely in PMMCs. Wang et al. [62] performed hot extrusion on $10 \mu \mathrm{m} \mathrm{SiCp} / \mathrm{AZ91}$ composites at $350{ }^{\circ} \mathrm{C}$, and they found that the particle agglomeration disappeared and the grains were refined, both of which resulted in the improved mechanical properties of micron PMMCs. Besides, increasing volume fraction of $\mathrm{SiCp}$ was beneficial 
to grain refinement as well as the improvements in strength and elastic modulus, but reduce the elongation of $\mathrm{Mg}$ matrix [62]. Nevertheless, Wang et al. [63] also found that the hot extrusion could cause the crack of $\mathrm{SiCp}$ and the interfacial debonding between $\mathrm{SiCp}$ and $\mathrm{Mg}$ matrix, which inevitably deteriorated the strength of the SiCp/AZ91 composite with high volume fraction (20 vol\%). The same phenomenon has also been obtained by the research on $10 \mu \mathrm{m}$ SiCp reinforced $\mathrm{Mg}-\mathrm{Zn}-\mathrm{Ca}$ composite [64]. Besides volume fraction, the particle size also had significant effect on the microstructure and mechanical properties of the as-extruded PMMCs based on the investigation of $\mathrm{SiCp} / \mathrm{Mg}-\mathrm{Al}-\mathrm{Ca}$ composite [65]. The results revealed that the size of $\mathrm{SiCp}$ could influence the shape and distribution of precipitated phase, and the most excellent mechanical properties were obtained when the size of $\mathrm{SiCp}$ is $5 \mu \mathrm{m}$.

To eliminate the secondary phase and improve the high-temperature deformation ability of PMMCs, it was usually solution-treated prior to hot extrusion. Shang et al. [66] attempted to extrude the as-cast $5 \mu \mathrm{m} 10 \mathrm{vol} \%$ $\mathrm{SiCp} / \mathrm{M}-\mathrm{Al}-\mathrm{Zn}$ composite directly at $320{ }^{\circ} \mathrm{C}$, and then the obtained YS, UTS and elongation of the composite were $\sim 310 \mathrm{MPa}, \sim 395 \mathrm{MPa}$ and $3.8 \%$, respectively. It was believed that the refinement of both $\mathrm{Mg}_{17} \mathrm{Al}_{12}$ phase and grain size were responsible for the high comprehensive mechanical properties caused by hot extrusion [66].

Sun et al. [67] considered that the high content of $\mathrm{Mg}_{17} \mathrm{Al}_{12}$ phase was the main reason for the excellent mechanical properties of $\mathrm{SiCp} / \mathrm{M}-\mathrm{Al}-\mathrm{Zn}$ composites. To obtained the fine-grained PMMCs with high content of $\mathrm{Mg}_{17} \mathrm{Al}_{12}$ phase, they attempted to extrude $5 \mu \mathrm{m} 10 \mathrm{vol} \%$ $\mathrm{SiCp} / \mathrm{AZ} 91$ with lower extrusion speed $(0.01-1 \mathrm{~mm} / \mathrm{s})$ at $250{ }^{\circ} \mathrm{C}$ [67]. At last, the PMMCs with the DRXed grain size of $\sim 0.5 \mu \mathrm{m}$ and the volume fraction of $\mathrm{Mg}_{17} \mathrm{Al}_{12}$ phase of 16-18 vol\% were obtained [67]. The interaction between $\mathrm{SiCp}$ and DRX was responsible for the high content of $\mathrm{Mg}_{17} \mathrm{Al}_{12}$. As the decrease in extrusion speed, the tensile strength of PMMCs increased, but the elongation of which was decreased [67]. When the extrusion speed drops to $0.01 \mathrm{~mm} / \mathrm{s}$, the YS and UTS could reach to $\sim 391 \mathrm{MPa}$ and $\sim 440 \mathrm{MPa}$, respectively, as shown in Fig. 1, which are superior to the existing research levels [67]. The nano$\mathrm{SiCp} / \mathrm{AZ91}$ composites were extruded by Nie et al. [68], and the results were similar to those of micron PMMCs. Above research indicated that the application of extrusion had obvious effect on grain refinement and improvement of particle distribution, both of which directly play a role in the improvement of YS and UTS of PMMCs.

\subsection{Rolling}

At present, only a few researches focused on the rolling behavior of PMMCs. Considering the nano-PMMCs with low particle content possessed better ductility, the nanoPMMCs were rolled firstly by the investigators. The 1 vol\% nano-SiCp/AZ31 composite was rolled by Liu et al. [69] at $350{ }^{\circ} \mathrm{C}$ with $15 \%$ reduction per pass, and the results showed that the grain size was refined and the distribution of nano$\mathrm{SiCp}$ became much more uniform with increasing rolling pass. After 11 passes, the YS was more than twice the as-cast conditions, but the YS and UTS anisotropy existed between parallel and vertical rolling directions [69]. Subsequently, Wang et al. [70] further explored the effect of $1 \mathrm{vol} \%$ nano$\mathrm{SiCp}$ on the microstructure and mechanical properties of AZ31 alloy during rolling, and they found that nano-SiCp can effectively inhibit the formation of shear bands and influence the texture strength of Mg matrix. At the same time, due to the inhibitory effect of nano-SiCp on the growth of DRXed grains, the regions with fine grains were formed in the nano-PMMCs, while the grains were large among these fine-grained regions [70]. This kind of bimodal-sized grains in the as-rolled nano-PMMCs was thought propitious to the improvement in mechanical properties. (a)

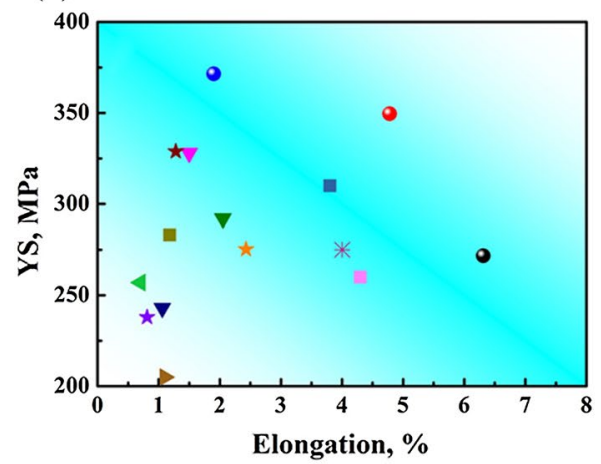

(b)

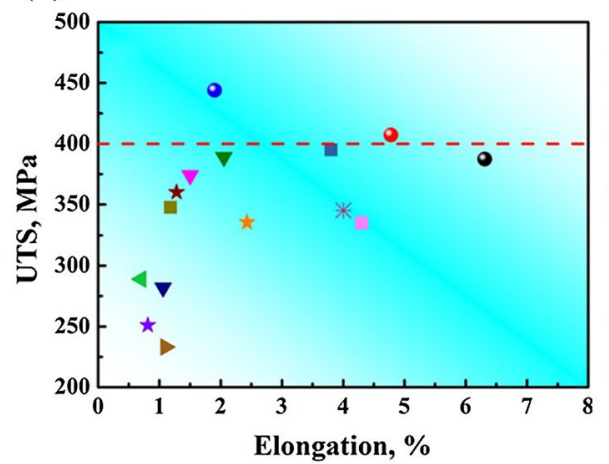

$1 \mathrm{~mm} / \mathrm{s}$, in present work $0.1 \mathrm{~mm} / \mathrm{s}$, in present work

$0.01 \mathrm{~mm} / \mathrm{s}$, in present w ork

$\checkmark$ N-lvol \%,EDTECAP

5 $\mu$ mlorol $\%, F D+E D$

F 5 ml0rol \%,FD

$10 \mu \mathrm{ml}$ \%ol $\%, \mathrm{FD}$

S-lvol\%,FD

S-lvol $\% \div 10 \mu \mathrm{m}-9 \mathrm{vol} \% \mathrm{FD}$

‥ $10 \mu \mathrm{m}-10 \mathrm{vol} \%, \mathrm{FD}$

$5 \mu \mathrm{ml0vol} \%, \mathrm{ED}$

$10 \mu \mathrm{mlOrol} \% \mathrm{ED}$

AZ91D/10vol\%ED

AZ9ID/15vol\%ED

* AZ91D/1rol.\%,ED

Fig. 1 Comparison of mechanical properties among SiCp/AZ91 composites extruded with different speeds and other AZ91 matrix composites reinforced with SiCp: a YS, b UTS. Reproduced from [67], with permission from Elsevier 
The microstructure evolution mechanism of $(0.1-3 \mu \mathrm{m})$ $Y \mathrm{Al}_{2 \mathrm{p}} / \mathrm{MgLiAl}$ composites during rolling process was conducted, and it was found that the distribution of $Y \mathrm{Al}_{2 \mathrm{p}}$ became much more uniform with increasing reduction amount of rolling [71]. Besides, the fragmentation of $Y \mathrm{Al}_{2 \mathrm{p}}$ was also found at the same time. Nevertheless, the precipitation of $\alpha$ phase in $\mathrm{MgLiAl}$ matrix was observed during the rolling process. The interface between $\alpha$ phase and $\beta$ matrix belonged to semi-coherent, and the existed specific orientation relationship was $(0002)_{\alpha} / /(110)_{\beta}[71]$. Beside $\alpha$ phase, the precipitated YAl particles were also found [71], which might be originated from the reaction between $Y$ element in $Y_{\mathrm{Al}}$ and $\mathrm{Al}$ element in $\mathrm{MgLiAl}$ matrix.

\subsection{Two-Step Deformation}

The two-step hot deformation process is a common method for refining grain size and improving mechanical properties of $\mathrm{Mg}$ alloys. As compared to the one-step extrusion or ECAP, the grains of $\mathrm{Mg}-0.6 \% \mathrm{Zr}$ alloy were significantly refined $(\sim 1 \mu \mathrm{m})$ after two-step deformation (extrusion + ECAP) [72]. Moreover, the super-plasticity of $\mathrm{Mg}-0.6 \% \mathrm{Zr}$ alloy after two-step deformation was investigated by Matsubara et al. [47], the results showed that the elongation of $\mathrm{Mg}-0.6 \% \mathrm{Zr}$ alloy could reach $400 \%$ at $100{ }^{\circ} \mathrm{C}$, which demonstrated good high-temperature plasticity. After subjecting the two-step deformation (extrusion + ECAP) to AZ31 alloy, the same results were also obtained by Stráská et al. [73]. The investigation of Ying et al. on ZK60 alloy showed that the basal plane texture was weakened and the YS was low after one-step ECAP; however, the grains were refined to $\sim 1 \mu \mathrm{m}$, and the YS and UTS are increased to $342 \mathrm{MPa}$ and $388 \mathrm{MPa}$, respectively, after the subsequent extrusion process [74].

Based on the investigation of two-step deformation on $\mathrm{Mg}$ alloy, the researchers began to apply two-step deformation on PMMCs. Wu et al. [75] carried out two-step hot deformation (forging + extrusion) on $5 \mu \mathrm{m} 10 \mathrm{vol} \% \mathrm{SiCp} / \mathrm{AZ} 91$ composites, and the results showed that the grains became much finer and the SiCp distributed much uniform after twostep deformation. Deng et al. [76] adopted the same two-step hot deformation as Wu et al. on $0.2 \mu \mathrm{m} 1.5 \mathrm{vol} \% \mathrm{SiCp} / \mathrm{AZ} 91$ composites, and the similar results were also obtained in submicron PMMCs. Recently, the nano-SiCp/AZ91 composite was fabricated through stirring casting by Qiao et al. [77], and then it was performed by hot extrusion and ECAP subsequently. The results confirmed that the application of two-step deformation was helpful to grain refinement, particle distribution as well as weakening basal plane texture of nano-PMMCs, all of which contributed to the improvement in YS and UTS.

\section{Deformation Mechanism of PMMCs}

The flow stress is closely related to temperature and strain rate for the material deformed at high temperature. The constitutive equation based on the relationship among flow stress, strain rate and temperature has important guiding significance for the material's hot deformation process. At present, the three constitutive equations of power, exponential and hyperbolic sinusoids are mainly used to reveal the high-temperature deformation behavior of materials. Based on the above constitutive equation, the stress index $n$ and the deformation activation energy $Q$ of the material under high-temperature deformation can be calculated. According to the $n$ and $Q$ values, the deformation mechanism of the material can be illustrated [78-83].

The micron PMMC $(10 \mu \mathrm{m} 10$ vol\% SiCp/AZ91 composite) was compressed at $250-400{ }^{\circ} \mathrm{C}$ by Wang et al. [84], and the results showed that both the peak stress and flow stress decreased with increasing temperature and strain rate. Based on the high-temperature compression curve analysis, the calculated $n$ and $Q$ were 5 and $99 \mathrm{~kJ} / \mathrm{mol}$, respectively, which was considered that the high-temperature deformation mechanism of this kind of PMMCs was the dislocation climbing mechanism controlled by grain boundary diffusion. The microstructure evolution of this kind of $10 \mu \mathrm{m} 10 \mathrm{vol} \% \mathrm{SiCp} / \mathrm{AZ} 91$ composite compressed at high temperature was also researched [85]. It revealed that the high-temperature compression was beneficial to improve the distribution of SiCp. Moreover, the compression temperature and strain rate could affect the generation of dislocations and twins and finally influenced the DRX behavior of micron PMMCs.

In addition to micron PMMCs, the researchers also carried out related research on the high-temperature deformation behavior of nano-PMMCs. Wang et al. [86] prepared nano-SiCp/AZ91 composite by a combination of stirred casting and ultrasonic dispersion. After analyzing the compression curves of nano-SiCp/AZ91 composite at $250-400{ }^{\circ} \mathrm{C}$, the deformation activation energy $Q$ was calculated to be $\sim 185 \mathrm{~kJ} / \mathrm{mol}$ [86], which was higher than the self-diffusion activation energy of pure magnesium $(135 \mathrm{~kJ} / \mathrm{mol})$ [87]. The deformation mechanism of nano-SiCp/AZ91 composite was thought as the dislocation climbing mechanism controlled by self-diffusion [86]. Further research of Nie et al. found that the addition of nanoparticles could also improve the deformation ability of AZ91 alloy under high-temperature conditions [88].

Prasad et al. [78] performed high-temperature compression on the as-extruded 1 vol\% nano- $\mathrm{Al}_{2} \mathrm{O}_{3} \mathrm{p} / \mathrm{Mg}$ composite at $300-500{ }^{\circ} \mathrm{C}$ and found that the optimum deformation conditions were located at $400-450{ }^{\circ} \mathrm{C}$ with the strain rate larger than $0.1 \mathrm{~s}^{-1}$. In addition, the deformation activation 
energy of $\mathrm{Al}_{2} \mathrm{O}_{3} \mathrm{p} / \mathrm{Mg}$ composites was also related to strain rate. At high strain rates, the $Q$ values of both $\mathrm{Mg}$ alloys and nano-PMMCs were close to the grain boundary diffusion activation energy $(92 \mathrm{~kJ} / \mathrm{mol})$, and the deformation behavior was influenced by grain boundary diffusion. At the low strain rate, the $Q$ values of $\mathrm{Mg}$ alloy and nanoPMMCs were $136 \mathrm{~kJ} / \mathrm{mol}$ and $305 \mathrm{~kJ} / \mathrm{mol}$, respectively, which were larger than the self-diffusion activation energy of pure magnesium $(135 \mathrm{~kJ} / \mathrm{mol})$, and the deformation behavior of which was thought to be controlled by lattice self-diffusion [78].

The 1.5 vol\% nano-Al/AZ31 material was fabricated by Zhong et al. [82] through DMD process. After being extruded, the high-temperature deformation behavior of the above nano-PMMCs was analyzed. Results indicated that the grain boundary sliding still played a main role in the finegrained PMMCs, while the existence of nanoparticles had a certain hindrance to grain boundary sliding. The 17 vol\% $2 \mu \mathrm{m} \mathrm{SiCp/ZK60} \mathrm{composite} \mathrm{prepared} \mathrm{by} \mathrm{powder} \mathrm{metallurgy}$ was extruded by Watanabe et al. [89], and then the grain size of only $\sim 1.7 \mu \mathrm{m}$ was obtained. After being subjected to tensile at $175-228{ }^{\circ} \mathrm{C}$, the deformation activation energy was calculated to be $97 \mathrm{~kJ} / \mathrm{mol}$, which was close to the grain boundary diffusion activation energy of pure magnesium [89]. Therefore, the deformation mechanism of $17 \mathrm{vol} \%$ $2 \mu \mathrm{m} \mathrm{SiCp/ZK60} \mathrm{composite} \mathrm{at} \mathrm{low} \mathrm{temperatures} \mathrm{was} \mathrm{con-}$ sidered to be grain boundary sliding mechanism controlled by grain boundary diffusion.

In general, the grain boundary sliding occurs much more easily with decreasing grain size, resulting in the reduction in deformation energy. As the particle existed in the $\mathrm{Mg}$ matrix, the deformation mechanism is inevitable changed owing to the variation of DRX behavior influenced by particle size. Even though some works have been done on the fine-grained PMMCs, the high-temperature deformation behavior of fine-grained PMMCs influenced by particle size and their coupling effect still need further investigation.

\section{DRX Behavior of PMMCs}

Generally, the dynamic recrystallization (DRX) of Mg alloy is absolutely different from that of static recrystallization. The main difference between them is the driving force. The driving force relates to the stored energy in $\mathrm{Mg}$ alloy during deformation process. The release of stored energy promotes the movement of dislocations and grain boundaries, which is helpful to the nucleation and growth of recrystallized grains. For static recrystallization, the stored energy decreases gradually during recrystallization process, and the nucleation of recrystallized grains will be stopped once the stored energy is used up. On the contrary, the stored energy of DRX will be provided continuously, which lead to the continuously occurrence of the DRXed nucleus during the whole hot deformation process.

As the harden particles existed in the Mg alloys, more dislocations can be generated during deformation process due to the deformation mismatch between the particles and $\mathrm{Mg}$ matrix. Meanwhile, the existence of particles also makes it hard for the movement of dislocations and grain boundaries. Thus, the recrystallization behavior of $\mathrm{Mg}$ alloy containing harden particles should be different from that of monolithic $\mathrm{Mg}$ alloy. The research has illustrated that the recrystallization behavior of PMMCs depends on particles size.

\section{(1) Large particles $(>1 \mu \mathrm{m})$}

As the size of harden particle is larger than $1 \mu \mathrm{m}$, the region with high-density dislocation and large orientation gradient can be formed in the vicinity of particle owing to the deformation mismatch between the particle and matrix, which is recognized as particle deformation zone (PDZ) [90, 91]. According to Ref. [89], the size of PDZ around harden particles is approximately $1.5-1.8$ times of the particle size. Figure 2 [92] shows the schematic of PDZ. Due to the high storage energy in PDZ, the nucleation of recrystallization can be promoted and this phenomenon was called as particle stimulated nucleation (PSN) mechanism [90, 91]. Regarding the PSN mechanism, a lot of researches have been carried out on aluminum matrix composites, and it was the large misorientation in PDZ and faster migration rate of the subgrain boundary around particles favorable for the formation of new large-angle grain boundaries [93, 94]. Besides, the misorientation was large among recrystallized grains formed

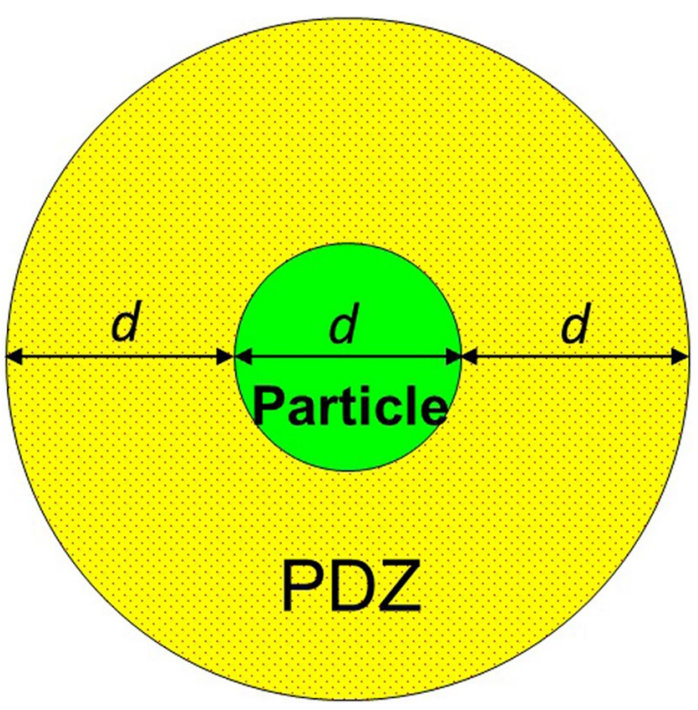

Fig. 2 Schematic of particle deformation zone (PDZ). Reproduced from [92], with permission from Elsevier 
through PSN, which was also beneficial to adjusting the texture of material [91].

During the recrystallization process, a stable recrystallization core can be developed only when the recrystallized core reaches a critical nucleation radius and the misorientation between adjacent grain boundaries is greater than $10^{\circ}$. Moreover, the occurrence of recrystallization is also related to the deformation temperature and strain rate. In general, the recrystallized nucleation is more likely to occur accompanying with increasing temperature and decreasing strain rate. Based on the investigation of $\mathrm{SiC}_{\mathrm{p}}$ reinforced $\mathrm{AZ91}$ composite, the DRXed rate of PMMCs during hot deformation was higher than that of monolith matrix alloy. This was contributed to the PDZ formed around micro-SiC $\mathrm{p}_{\mathrm{p}}$ during hot deformation, which was helpful to promote the nucleation of DRXed grains. PDZ is about one diameter along the interface between particle and $\mathrm{Mg}$ matrix, which enlarges with increasing size of $\mathrm{SiC}_{\mathrm{p}}$ [95].

In addition, Wang studied the effect of necklace-like particle distribution on DRX behavior, and the results showed that the DRXed grains mainly distributed along SiCp in the shape of a necklace at grain boundaries, as shown in Fig. 3 [96]. With the proceeding of hot deformation, the extent of DRX increased and it extended to the entire matrix gradually. As the promoting effect of micron particle on the nucleation of DRXed grains, the micron PMMCs usually possessed fine grains as compared to monolithic $\mathrm{Mg}$ alloy $[65,97,98]$.

(2) Fine particles $(<1 \mu \mathrm{m})$
The size of PDZ strongly depends on particle size, thus the PDZ size is very small, and its promotion effect on recrystallization nucleation is negligible as the particle size is finer than $1 \mu \mathrm{m}$. Prasad et al. [78] thought that the fine particles had a strong pinning effect on grain boundary, so the grain boundary was not easy to slip, rotate and migrate, and this nearly does not change the grain size in $\mathrm{Mg}$ matrix during hot deformation process. Even though the fine particles had a little effect on the volume fraction of DRXed grains, Robson et al. [99] found that the recrystallization process in $\mathrm{Mg}$ matrix could be delayed when it is deformed at low strain rate. Chan et al. [100] also found that the fine particles had the pinning effect on both the low-angle grain boundaries and high-angle grain boundaries, especially in the initial stage of recrystallization. Then, they thought the fine particles had the hinder effect on the nucleation of recrystallization in $\mathrm{Mg}$ matrix [100].

Pervious works have demonstrated that the fine particles had a certain inhibitory effect on recrystallized nucleation; however, the researches [30, 32, 87] on nano-PMMCs [30] have shown that the fine particles could promote the nucleation of DRXed grains, which made the grains in Mg matrix remarkably be refined after hot deformation. Similar results were also obtained in submicron PMMCs, and it was thought that the fine particles could not only promote the generation of dislocations owing to deformation mismatch of the particles with matrix, but also lead to the increase of dislocation density due to their pinning effect on dislocations [37, 101]. So, the fine particles were thought propitious to the nucleation of DRXed grains and the corresponded DRXed
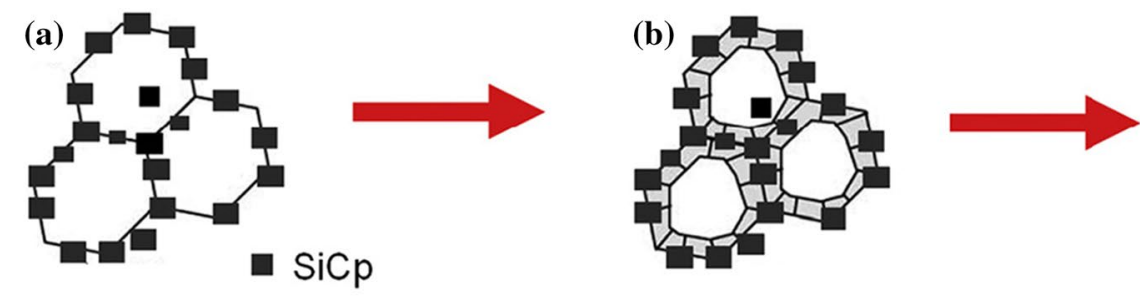

(c)

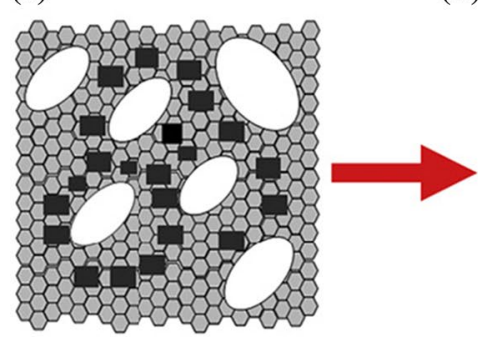

(d)

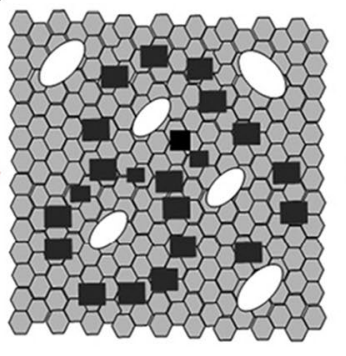

(e)

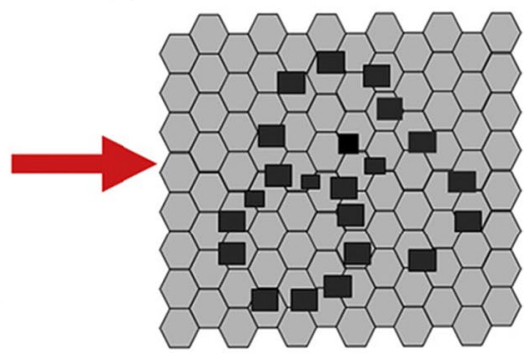

Fig. 3 Schematic diagram of the necklace DRX mechanism of $\mathrm{Mg}$ matrix composites with necklace-type particle distribution: a particles distribute along the grain boundaries; $\mathbf{b}$ PDZs are formed along grain boundaries; c DRX preferentially occurs along the initial grain boundaries due to PSN; d DRX extends from intergranular areas of initial grains to initial transgranular areas; e DRX is completed. Reproduced from [96], with permission from Elsevier 
mechanism influenced by fine particles was also proposed and is shown in Fig. 4 [37, 101].

\section{Recrystallized Texture of PMMCs}

Usually, DRXed texture can be formed in Mg alloy after hot deformation process, such as rolling, forging, and extrusion, etc. Thus, the influence of particles on DRX will inevitably act on the texture of $\mathrm{Mg}$ alloys. In fact, the research of the influence of particles on recrystallized texture has been noticed at the beginning of the investigation on particle reinforced $\mathrm{Al}$ matrix composite. At the initial stage of the research on this aspect, there was no consensus on whether the PSN could influence the recrystallized texture or not. According to the research of Ref [102], the texture became more random and the texture intensity was weakened after the occurrence of recrystallization. Chan et al. [100] found that the texture intensity was strengthened after recrystallization, and then a typical recrystallized texture could be formed. The difference from work between Bleck et al. and Chan et al. may be derived from their different measurement methods for crystal orientation. The X-ray method adopted by Bleck et al. lacked accuracy. Nevertheless, the research of Chan et al. based on TEM observation was too microscopic to reflect the overall orientation characteristics of the sample. However, it was possible to directly observe the nucleation and growth stages of recrystallization by EBSD, which would give a clearer understanding to the evolution of recrystallized texture.

Habiby et al. [103] used EBSD technique to analyze the grain orientation before and after recrystallization, and the

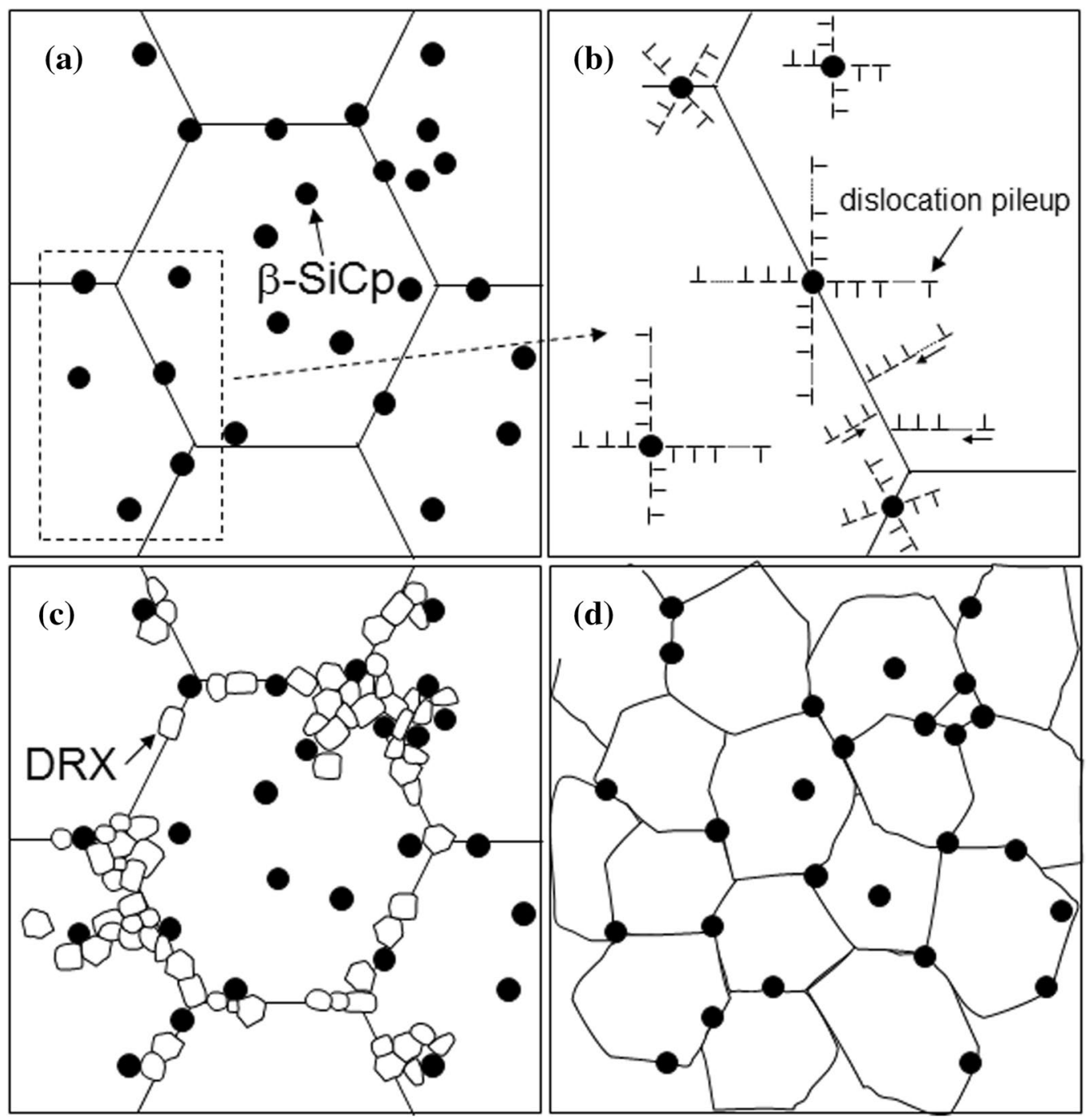

Fig. 4 Schematic illustration of DRX influenced by submicron SiCp during hot deformation: a microstructure before DRX, b high-density dislocations around submicron SiC particles, c DRX nucleation pri- ority near submicron $\mathrm{SiC}$ particles and at grain boundaries, $\mathbf{d}$ microstructure after DRX. Reproduced from [101], with permission from Elsevier 
result indicated that the recrystallized texture was closely related to both the initial texture and orientation of recrystallized nucleus. It was believed that the influence of PSN on recrystallized texture depended on the recrystallized temperature [103]. At high temperature, recrystallization nucleated at the center of PDZ, and the formed texture was random. However, the nucleation was formed by the migration of subgrain boundary at low temperature, so the obtained recrystallized texture was similar to the initial texture of the material, which was consistent well with the results of Orsund et al. [104].

In recent years, related research on the recrystallized texture of PMMCs has also been carried out. Robson et al. [92] studied the Mg-Mn alloy containing micron particles and found that recrystallization mainly occurred inside the grains and PSN had a little effect on the recrystallized texture. Based on the research of the as-forged Mg alloys [105], the occurrence of PSN could weaken texture but not change the type of texture. Radi et al. [32] also obtained the same results in nano-PMMCs, and it was believed that nano- $\mathrm{Al}_{2} \mathrm{O}_{3}$ particles could influence the intensity of recrystallized texture, but had no effect on changing the type of texture.

The recrystallized texture of PMMCs depends on the hot deformation technology. Both the monolithic AZ91 alloy and $10 \mu \mathrm{m} 10$ vol\% SiCp/AZ91 composite were forged by Deng et al [56], and they found that the typical forging texture with the (0002) basal plane perpendicular to forging direction was formed after forging process, as shown in Fig. 5, and the existence of micron SiCp weakened the intensity of texture, but had no influence on the type of texture. On the subsequent work of Deng et al, the forged AZ91 alloy and PMMCs were extruded [95]; the result indicated that the (0002) basal plane was parallel to extrusion direction and the prismatic plane was perpendicular to the extrusion direction, as shown in Fig. 6. Besides, their results also revealed that the type of texture was independent of the particle size. Regardless of fine $(<1 \mu \mathrm{m})$ or large $(>1 \mu \mathrm{m})$ particles, both of them could not change the texture type, but only weakened the intensity of texture [95]. Even so, the weakening effect of particles on texture intensity depended on particle size. Owing to the deformation mismatch between particle and matrix, the PDZ with high-density dislocation and large orientation gradient could be formed in the vicinity of the large particles $(>1 \mu \mathrm{m})$ during hot deformation process, which was propitious to the nucleation of recrystallization. After recrystallization, the texture was random in PDZ, which led to the weakening of texture intensity after hot deformation. Accompanying with decreasing particles size, the size of PDZ was also decreased, thus its effect on the nucleation of recrystallization was also weakened. As a consequent, the effect PDZ on weakening texture intensity was decreased.

\section{Prospects}

Introducing particles into $\mathrm{Mg}$ matrix aims to improve the $\mathrm{Mg}$ alloy's comprehensive mechanical properties, such as strength, modulus, elongation, dimensional stability, wear resistance. All the properties are related to the fabrication and hot deformation processing technology. Nevertheless, the particle size and volume fraction of PMMCs also play an important role. To obtain the PMMCs with comprehensive mechanical properties, the multi-sale particle reinforced $\mathrm{Mg}$ matrix composites become much more popular than those with single-sized particles. However, how to realize the uniform particle distribution and increase the amount of fine (nano- or submicron) particles in multi-sale PMMCs is still a question. Recent researches have shown that the nanosecondary phase precipitates in the Mg alloy or PMMCs during hot deformation process, and it also demonstrates that the micron PMMCs containing nano-precipitates processes better mechanical properties than the multi-scale PMMCs in the present research. So, processing the PMMCs by the combination of adding large particles and dynamic precipitated fine phase is promising way.

The dynamic precipitation process is accompanied with the occurrence of dynamic recrystallization in PMMCs

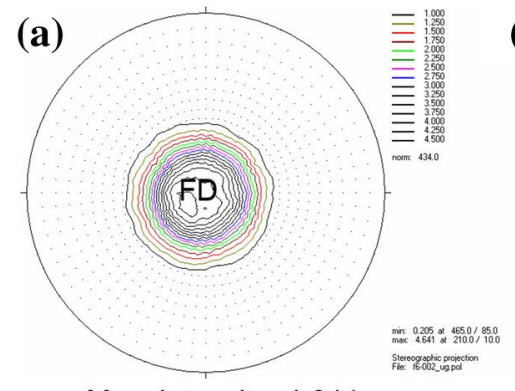

Max. Intensity: 4.641

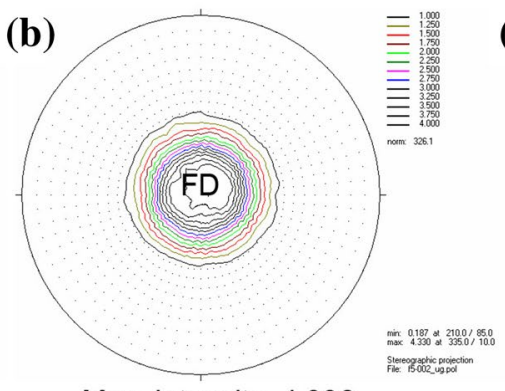

Max. Intensity: 4.330

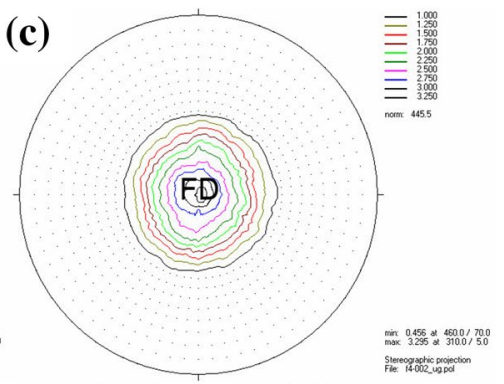

Max. Intensity: 3.295

Fig. 5 Basal pole figures of the SiCp/AZ91 composite forged at a $320{ }^{\circ} \mathrm{C}$, b $370{ }^{\circ} \mathrm{C}, \mathbf{c} 420{ }^{\circ} \mathrm{C}$. Reproduced from [56], with permission from Elsevier 

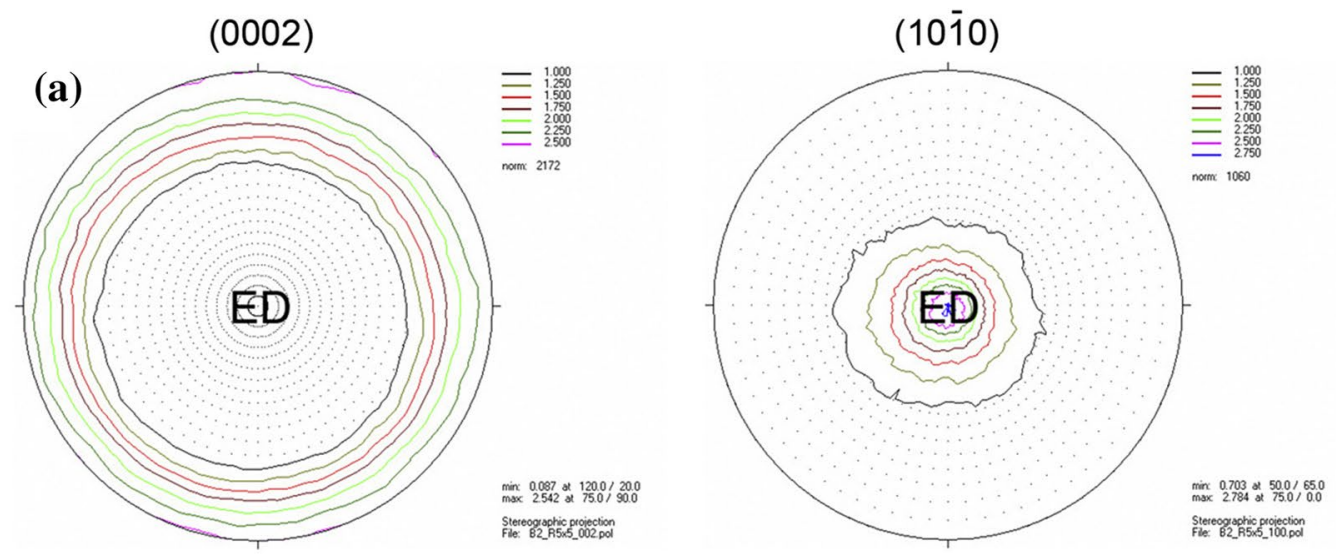

Max. Intensity: 2.542

Max. Intensity: 2.784
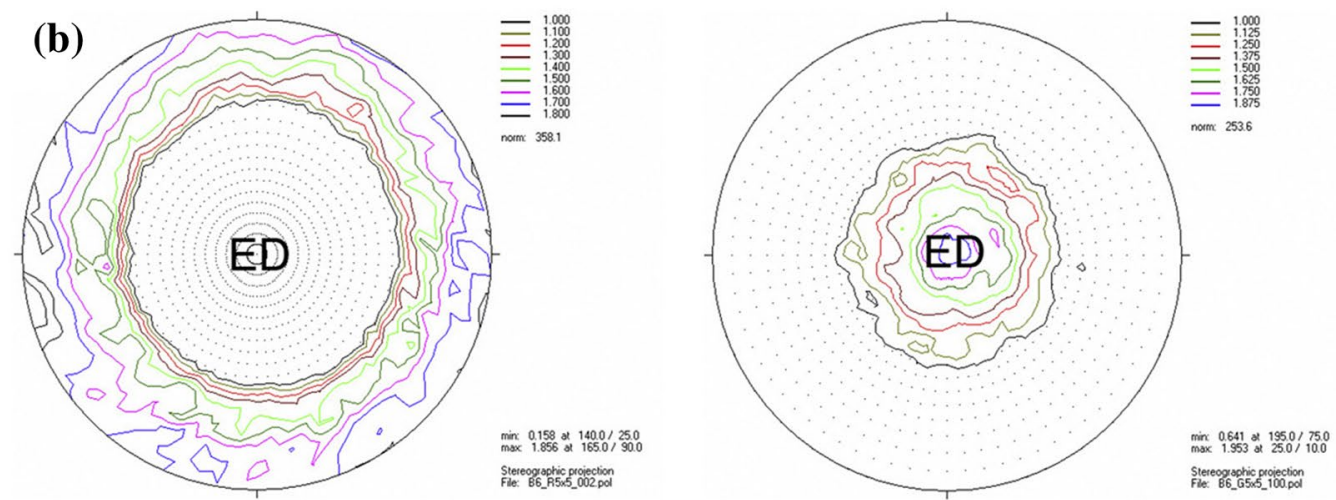

Max. Intensity: 1.856

Max. Intensity: 1.953

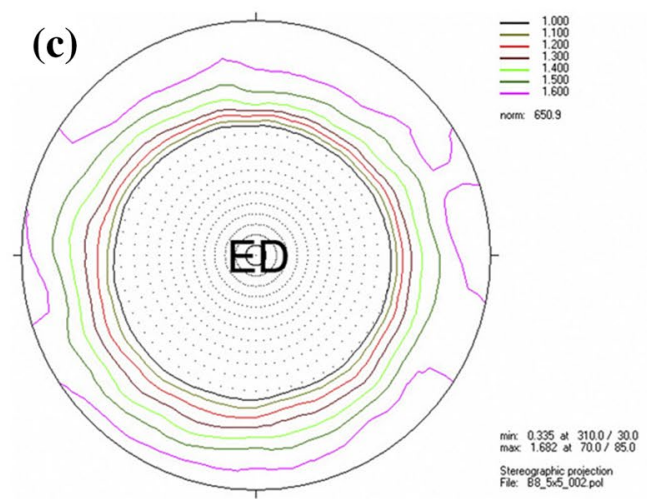

Max. Intensity: 1.682

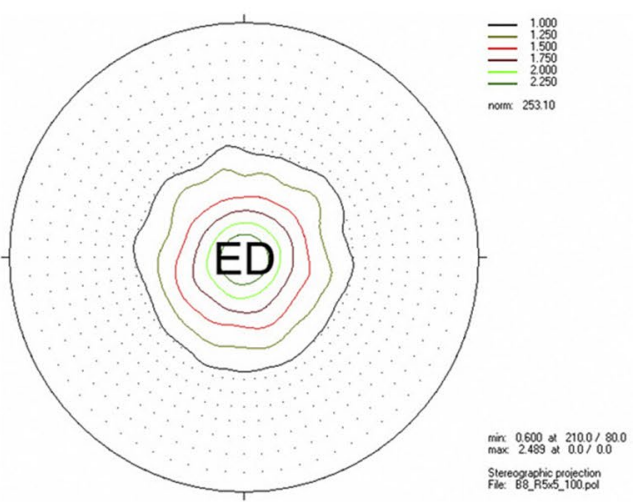

Max. Intensity: 2.489

Fig. 6 Pole figures of the a AZ91 alloy, b $0.2 \mu \mathrm{m} 5 \%$, c $10 \mu \mathrm{m} 5 \%$ SiCp/AZ91 composites after hot deformation. Reproduced from [92], with permission from Elsevier

during hot deformation process [106]. Moreover, the occurrence of dynamic recrystallization leads to the grain refinement, which will provide more grain boundaries and is propitious to the precipitation of secondary phase. On the contrary, the precipitated secondary phase can also influence the nucleation and growth of DRXed grains. It should be noted that the PDZ with high-density dislocation and large orientation gradient can be formed in the vicinity of the large particles ( $>1 \mu \mathrm{m})$ during hot deformation process, which is not only propitious to the nucleation of recrystallization, but also be helpful to the precipitation of secondary phase. Thus, it can be concluded that a closely associated relationship exists among precipitate, dynamic recrystallization and PDZ, all of which will inevitable reflect on the microstructure and mechanical properties of PMMCs after hot deformation. The relationship 
among DRX, dynamic precipitation and PDZ in PMMCs still needs further investigation.

Acknowledgements This work was supported by the National Natural Science Foundation of China (Grant Nos. 51771128 and 51201112), the Projects of International Cooperation in Shanxi (Grant No. 201703D421039) and the Natural Science Foundation of Shanxi (Grant No. 201601D011034). The authors also thank the Support from Program for the Outstanding Innovative Teams of Higher Learning Institutions of Shanxi.

\section{References}

[1] F.S. Pan, M.B. Yang, X.H. Chen, J. Mater. Sci. Technol. 32, 1211 (2016)

[2] X.J. Wang, D.K. Xu, R.Z. Wu, X.B. Chen, Q.M. Penge, L. Jin, Y.C. Xing, Z.Q. Zhang, Y. Liu, X.H. Cheng, G. Chen, K.K. Deng, H.Y. Wang, J. Mater. Sci. Technol. 34, 245 (2018)

[3] S.H. You, Y.D. Huang, K.U. Kainer, N. Hort, J. Magnes. Alloy. 5, 239 (2017)

[4] K.K. Alaneme, E.A. Okotete, J. Magnes. Alloy. 5, 460 (2017)

[5] X.J. Wang, X.S. Hu, W.Q. Liu, J.F. Du, K. Wu, Y.D. Huang, Mater. Sci. Eng. A. 682, 491 (2017)

[6] M. Haghshenas, J. Magnes. Alloy. 5, 189 (2017)

[7] X.J. Wang, K.B. Nie, X.J. Sa, X.S. Hu, K. Wu, M.Y. Zheng, Mater. Sci. Eng. A 534, 60 (2012)

[8] Q.C. Jiang, H.Y. Wang, B.X. Ma, Y. Wang, F. Zhao, J. Alloys Compd. 386, 177 (2005)

[9] M.K. Habibi, A.M.S. Hamouda, M. Gupta, Compos. Sci. Technol. 72, 290 (2012)

[10] X.Q. Zhang, H.W. Wang, L.H. Liao, X.Y. Teng, N.H. Ma, Mater. Lett. 59, 2105 (2005)

[11] C.F. Zhang, T.Y. Fan, W. Cao, J. Ding, D. Zhang, Compos. Sci. Technol. 69, 2688 (2009)

[12] H.Z. Ye, X.Y. Liu, J. Mater. Sci. 39, 6153 (2004)

[13] H. Hu, J. Mater. Sci. 33, 1579 (1998)

[14] A. Luo, Metall. Mater. Trans. A 26A, 2445 (1994)

[15] X.J. Wang, K. Wu, D.L. Peng, H.F. Zhang, M.Y. Zheng, W.X. Wang, Trans. Nonferrous Met. Soc. China 16, 1840 (2006)

[16] L.Q. Chen, Y.T. Yao, Acta Metall. Sin. (Engl. Lett.) 27, 762 (2014)

[17] Y. Cai, M.J. Tan, G.J. Shen, H.Q. Su, Mater. Sci. Eng. A 282, $232(2000)$

[18] X.J. Wang, K. Wu, W.X. Huang, H.F. Zhang, M.Y. Zheng, D.L. Peng, Compos. Sci. Technol. 67, 2253 (2007)

[19] S.A. Sajjadi, H.R. Ezatpour, M.P. Torabi, Mater. Des. 34, 106 (2012)

[20] X.J. Wang, N.Z. Wang, L.Y. Wang, X.S. Hu, K. Wu, Y.Q. Wang, Y.D. Huang, Mater. Des. 57, 638 (2014)

[21] A.R. Vaidya, J.J. Lewandoowski, Mater. Sci. Eng. A 220, 85 (1996)

[22] T.J. Chen, X.D. Jiang, Y. Ma, Y.D. Li, Y. Hao, J. Alloys Compd. 496, 218 (2010)

[23] Z. Zhang, D.L. Chen, Scripta Mater. 54, 1321 (2006)

[24] K.B. Nie, K.K. Deng, X.J. Wang, W.M. Gan, F.J. Xu, K. Wu, M.Y. Zheng, J. Alloys Compd. 622, 1018 (2015)

[25] S.F. Hassan, M. Gupta, Mater. Sci. Eng. A 392, 163 (2005)

[26] S.C. Tjong, Adv. Eng. Mater. 9, 639 (2007)

[27] L.Y. Chen, D. Weiss, Manuf. Lett. 2, 62 (2013)

[28] L.Y. Chen, J.Y. Peng, Scripta Mater. 69, 634 (2013)

[29] K.B. Nie, X.J. Wang, K. Wu, X.S. Hu, M.Y. Zheng, L. Xu, Mater. Sci. Eng. A 528, 8709 (2011)
[30] M. Habibnejad-Korayem, R. Mahmudi, W.J. Poole, Mater. Sci. Eng. A 519, 198 (2009)

[31] C.S. Goh, J. Wei, L.C. Lee, M. Gupta, Acta Mater. 55, 5115 (2007)

[32] Y. Radi, R. Mahmudi, Mater. Sci. Eng. A 527, 2764 (2010)

[33] S. Hwang, C. Nishimura, Scripta Mater. 44, 2457 (2001)

[34] S.F. Hassan, M. Gupta, J. Alloys Compd. 457, 244 (2008)

[35] K.K. Deng, K. Wu, Y.W. Wu, K.B. Nie, M.Y. Zheng, J. Alloys Compd. 504, 542 (2010)

[36] H. Ferkel, B.L. Mordike, Mater. Sci. Eng. A 298, 193 (2001)

[37] K.K. Deng, J.Y. Shi, C.J. Wang, X.J. Wang, Y.W. Wu, K.B. Nie, K. Wu, Compos. A 43, 1280 (2012)

[38] M.J. Shen, X.J. Wang, M.F. Zhang, X.S. Hu, M.Y. Zheng, K. Wu, Mater. Sci. Eng. A 601, 58 (2014)

[39] S. Sankaranarayanan, R.K. Sabat, S. Jayalakshmi, S. Suwas, M. Gupta, J. Alloys Compd. 575, 207 (2013)

[40] S. Sankaranarayanan, S. Jayalakshmi, M. Gupta, J. Magnes. Alloy 2, 13 (2014)

[41] A. Mallicka, K.S. Tun, M. Gupta, Mater. Sci. Eng. A 551, 222 (2012)

[42] M.Y. Zheng, X.G. Qiao, S.W. Xu, K. Wu, S. Kamado, Y. Kojima, Mater. Sci. Forum 488, 589 (2005)

[43] Y.C. Yuan, M. Aibin, X.F. Gou, J.H. Jiang, A. Godfred, D. Song, H. Liu, Mater. Sci. Eng. A 677, 125 (2016)

[44] J. Suh, J. Victoria-Hernández, D. Letzig, R. Golle, W. Volk, Mater. Sci. Eng. A 699, 159 (2016)

[45] M.R. Barnett, Z. Keshavarz, A.G. Beer, D. Atwell, Acta Mater. 52, $5093(2004)$

[46] A. Yamashita, Z. Horita, T.G. Langdon, Mater. Sci. Eng. A 300, 142 (2000)

[47] K. Matsubara, Y. Miyahara, Z. Horita, T.G. Langdon, Acta Mater. 51, 3073 (2003)

[48] T. Mukai, M. Yamanoi, H.W. Watanabe, K. Higashi, Scripta Mater. 45, 89 (2001)

[49] W.J. Kim, C.W. An, Y.S. Kim, S.I. Hong, Scripta Mater. 47, 39 (2002)

[50] E. Dogan, S. Wang, M.W. Vaughan, I. Karaman, Acta Mater. 116, 1 (2016)

[51] S. Ferrasse, V.M. Segal, S.R. Kalidindi, F. Alford, Mater. Sci. Eng. A 368, 28 (2004)

[52] A.A. Mohamed, Y.C. Wang, P.H.R. Pereira, Y.W. Wang, S.K. Li, Y.H. Terence, G. Langdon, Mater. Sci. Eng. A 712, 146 (2018)

[53] M. Peter, V. Jozef, K. Robert, B. Jan, K. Jiří, J. Miloš, S. Jitka, Mater. Sci. Eng. A 708, 193 (2017)

[54] J.H. Jia, W. Liang, F.Y. Han, H.X. Wang, D. Zhao, Rare Metal Mater. Eng. 42, 1268 (2013)

[55] W.M. Gan, K. Wu, M.Y. Zheng, X.J. Wang, H. Chang, H.G. Brokmeier, Mater. Sci. Eng. A 516, 283 (2009)

[56] K.K. Deng, K. Wu, X.J. Wang, Y.W. Wu, X.S. Hu, M.Y. Zheng, W.M. Gan, H.G. Brokmeier, Mater. Sci. Eng. A 527, 1630 (2010)

[57] K.K. Deng, X.J. Wang, W.M. Gan, Y.W. Wu, K.B. Nie, K. Wu, M.Y. Zheng, H.G. Brokmeier, Mater. Sci. Eng. A 528, 1707 (2011)

[58] K.B. Nie, K.K. Deng, X.J. Wang, T. Wang, K. Wu, Mater. Charact. 124, 14 (2017)

[59] W.J. Liao, B. Ye, L. Zhang, H. Zhou, W. Guo, Q.D. Wang, W.Z. Li, Mater. Sci. Eng. A 642, 49 (2015)

[60] W. Guo, Q.D. Wang, W.Z. Li, H. Zhou, L. Zhang, W.J. Liao, J. Compos. Mater. 51, 681 (2016)

[61] W. Guo, Q.D. Wang, W.Z. Li, H. Zhou, L. Zhang, W.J. Liao, J. Alloys Compd. 552, 409 (2013)

[62] X.J. Wang, X.S. Hu, K.B. Nie, K. Wu, M.Y. Zheng, Trans. Nonferrous Met. Soc. China 22, 1912 (2012)

[63] X.J. Wang, X.S. Hu, K. Wu, L.Y. Wang, Y.D. Huang, Mater. Sci. Eng. A 636, 138 (2015) 
[64] X.J. Wang, K.B. Nie, X.S. Hu, Y.Q. Wang, X.J. Sa, K. Wu, J. Alloys Compd. 532, 78 (2012)

[65] X. Zhang, K.K. Deng, W.J. Li, H.X. Wang, K.B. Nie, F.J. Xu, W. Liang, Mater. Sci. Eng. A 647, 15 (2015)

[66] S.J. Shang, K.K. Deng, K.B. Nie, J.C. Li, S.S. Zhou, F.J. Xu, J.F. Fan, Mater. Sci. Eng. A 610, 243 (2014)

[67] X.F. Sun, C.J. Wang, K.K. Deng, K.B. Nie, X.C. Zhang, X.Y. Xiao, J. Alloys Compd. 732, 328 (2018)

[68] K.B. Nie, X.J. Wang, L. Xu, K. Wu, X.S. Hu, M.Y. Zheng, J. Alloys Compd. 512, 355 (2012)

[69] W.Q. Liu, X.S. Hu, X.J. Wang, K. Wu, M.Y. Zheng, Mater. Des. 93, 194 (2016)

[70] X.J. Wang, W.Q. Liu, X.S. Hu, K. Wu, Mater. Sci. Eng. A 715, 49 (2018)

[71] H.L. Wang, G.Q. Wu, D.C. Zhang, J.G. Lin, L.J. Gong, M. Ma, Q. Peng, Mater. Charact. 104, 86 (2015)

[72] Z. Horita, K. Matsubara, K. Makii, T.G. Langdon, Scripta Mater. 47, 255 (2002)

[73] J. Stráská, M. Janeček, J. Čížek, J. Stráský, B. Hadzima, Mater. Charact. 94, 69 (2014)

[74] T. Ying, J.P. Huang, M.Y. Zheng, K. Wu, Trans. Nonferrous Met. Soc. China 22, 1896 (2012)

[75] K. Wu, K.K. Deng, K.B. Nie, Y.W. Wu, X.J. Wang, X.S. Hu, M.Y. Zheng, Mater. Des. 31, 3929 (2010)

[76] K.K. Deng, C.J. Wang, X.J. Wang, K. Wu, M.Y. Zheng, Mater. Des. 38, 110 (2012)

[77] X.G. Qiao, T. Yinga, M.Y. Zheng, E.D. Wei, K. Wu, X.S. Hu, W.M. Gan, H.G. Brokmeier, I.S. Golovin, Mater. Charact. 121, $222(2016)$

[78] Y.V.R.K. Prasad, K.P. Rao, M. Gupta, Compos. Sci. Technol. 69, 1070 (2009)

[79] H. Li, H. Wang, M. Zeng, X. Liang, H. Liu, Compos. Sci. Technol. 71, 925 (2011)

[80] L. Qi, Z. Wang, J. Zhou, L. Su, H. Li, Compos. Sci. Technol. 71, 955 (2011)

[81] M. Srinivasan, C. Loganathan, R. Narayanasamy, V. Senthilkumar, Q.B. Nguyen, M. Gupta, Mater. Des. 47, 449 (2013)

[82] T. Zhong, K.P. Rao, Y.V.R.K. Prasad, F. Zhao, M. Gupta, Mater. Sci. Eng. A 589, 41 (2014)

[83] C.J. Wang, K.K. Deng, W. Liang, J. Mater. Res. 33, 1723 (2018)

[84] X.J. Wang, X.S. Hu, K. Wu, K.K. Deng, W.M. Gan, C.Y. Wang, M.Y. Zheng, Mater. Sci. Eng. A 492, 481 (2008)

[85] X.J. Wang, X.S. Hu, Y.Q. Wang, K.B. Nie, K. Wu, M.Y. Zheng, Mater. Sci. Eng. A 559, 139 (2013)

[86] T. Wang, K.B. Nie, K.K. Deng, W. Liang, J. Mater. Res. 31, 3437 (2016)

[87] H.J. Frost, M.E. Ashby, Deformation mechanism maps (Pergamon Press, Oxford, 1982)

[88] K.B. Nie, X.K. Kang, K.K. Deng, T. Wang, Y.C. Guo, H.X. Wang, Nanomaterials 8, 82 (2018)

[89] H. Watanabe, T. Mukai, Scripta Mater. 42, 249 (2000)

[90] R.D. Doherty, D.A. Hughes, F.J. Humphreys, J. Juul Jonas, D.J. Jensen, M.E. Kassner, W.E. King, T.R. Mcnelley, H.J. McQueen, A.D. Rollett, Mater. Sci. Eng. A 238, 219 (1997)
[91] J.D. Robson, D.T. Henry, B. Davis, Acta Mater. 57, 2739 (2009)

[92] X.F. Sun, C.J. Wang, K.K. Deng, J.W. Kang, Y. Bai, K.B. Nie, S.J. Shang, J. Alloys Compd. 727, 1263 (2017)

[93] E.A. Ball, P.B. Prangnell, Scr. Metall. Mater. 31, 111 (1994)

[94] G.W. Lorimer, L.W.F. Mackenzie, F.J. Humphreys, T. Wilks, Mater. Sci. Forum 448, 99 (2005)

[95] K.K. Deng, Y.W. Wu, X.J. Wang, X.S. Hu, K. Wu, W.M. Gan, Mater. Sci. Eng. A 543, 158 (2012)

[96] X.J. Wang, X.S. Hu, K.B. Nie, K.K. Deng, K. Wu, M.Y. Zheng, Mater. Sci. Eng. A 545, 38 (2012)

[97] C.J. Wang, K.K. Deng, S.S. Zhou, W. Liang, Acta Metall. Sin. (Engl. Lett.) 29, 527 (2016)

[98] H. Chang, C.J. Wang, K.K. Deng, K. Su, L. Liao, H.X. Wang, L.B. Tong, Rare Metal Mater. Eng. 47, 1377 (2018)

[99] J.D. Robson, D.T. Henry, B. Davis, Mater. Sci. Eng. A 528, 4239 (2011)

[100] H.M. Chan, F.J. Humphreys, Acta Mater. 32, 235 (1984)

[101] K.K. Deng, X.J. Wang, M.Y. Zheng, K. Wu, Mater. Sci. Eng. A 560, 824 (2013)

[102] W. Bleck, H.J. Bunge, Acta Mater. 29, 1401 (1981)

[103] F. Habiby, F.J. Humphreys, Scripta Mater. 30, 787 (1994)

[104] R. Orsund, E. Nes, Scripta Mater. 22, 671 (1988)

[105] N. Stanford, M. Barnett, Scripta Mater. 58, 179 (2008)

[106] C.J. Wang, K.K. Deng, K.B. Nie, S.J. Shang, Mater. Sci. Eng. A 656, 102 (2016)

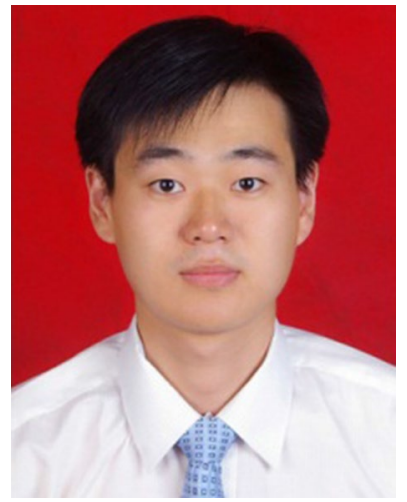

Dr. Kun-Kun Deng was born in 1983 and was awarded Ph. D in Harbin University of Technology in 2011. After graduation, he worked in the College of Materials Science and Engineering, Taiyuan University of Technology. At the same time, he continued his research work on the design, fabrication and processing of advanced $\mathrm{Mg}$-based material in. Now, he is the vice chairman of Youth Committee in Magnesium Alloy Branch of Chinese Materials Research Society. He was denoted as young academic pacemaker of Shanxi Province in 2018. He has held two projects of National Nature Science Foundation of China, one project of Specialized Research Fund for the Doctoral Program of Higher Education, one Project of International Cooperation in Shanxi and two projects of Natural Science Foundation of Shanxi. He has published more than 60 articles. The time cited is more than 840 (without selfcitations), and the $\mathrm{H}$-index is 22 . In addition, he has published one academic monograph and acquired eight Chinese patents. 